\title{
STRATEGI PEMASARAN DALAM RANGKA MENINGKATKAN PENJUALAN BENQ INTERACTIVE FLAT PANEL
}

\author{
Mike Avelinus Thendry \\ Program Studi Magister Manajemen Universitas Tarumanagara \\ mikeavelinus@gmail.com \\ Dr Anas Lutfi \\ Program Studi Magister Manajemen Universitas Tarumanagara
}

\begin{abstract}
Technological developments currently occur in several fields such as technological developments in the field of presentation. The latest presentation technology today is by using interactive flat panel where with this technology can provide a very good experience to its users. The purpose of the research is to obtain a description of marketing strategic steps that should be done by PT Datascrip in an effort to increase sales from Benq interactive flat panel and assess the extent to which the effectiveness of marketing strategies applied. The method used in this research is by qualitative descriptive method and by doing SWOT analysis (EFE and IFE matrix). The results of the EFE and IFE matrix analysis show that BenQ interactive flat panel products in overcoming threats are above average or show that BenQ interactive flat panel products have the ability to reach existing opportunities and internal management of PT Datascrip has strong enough capital to compete with competitors. The conclusion of this research is marketing strategy that can be done that is market development strategy, market penetration, and product development.
\end{abstract}

Keywords : market development strategy, market penetration, product development, interactive flat panel, swot analysis

\section{PENDAHULUAN}

Di zaman yang semakin modern ini, banyak sekali teknologi yang telah berkembang yang membuat manusia semakin mudah untuk melakukan apapun. Perkembangan teknologi ini terjadi dibeberapa bidang yakni salah satu nya adalah teknologi dibidang presentasi. Sekarang ini, teknologi semakin canggih, dan membuat presentasi menjadi lebih menarik. Terbaru, terdapat teknologi presentasi dengan menggunakan interactive flat panel dimana dengan teknologi ini dapat memberikan pengalaman yang sangat baik terhadap penggunanya. pengganti papan tulis, proyektor, papan tulis interaktif dan lainnya.

Pada penelitian kali ini, penulis akan mengerucutkan pada merek BENQ interactive flat panel, yang mana mempunyai banyak sekali kompetitor yang bermain di Indonesia seperti smarboard, mondopad infocus, viewsonic, dll. Penjualan dari BenQ interactive flat panel masih tergolong biasa-biasa saja dari tahun 2015-2016 . dibandingkan dengan brand lain. Oleh karena itu, strategi dalam menjalankan suatu usaha agar bisa bersaing dengan kompetitor bahkan melebihi sangat penting dan akan menjadi suatu tolak ukur yang utama agar usaha penjualan produk ini dapat berkembang menjadi lebih besar dan dapat dikenal oleh masyarakat luas. Oleh karena itu, tentu banyak sekali strategi-strategi yang harus direncanakan dan dijalankan agar usaha penjualan BENQ interactive flat panel ini dapat menjadi lebih berkembang

Tujuan dari penelitian yang dilakukan adalah memperoleh gambaran langkah-langkah strategis pemasaran yang sebaiknya dilakukan oleh PT Datascrip dalam upaya meningkatkan penjualan dari Benq interactive flat panel. 


\section{TINJAUAN PUSTAKA}

Pengertian Strategi Pemasaran bertujuan untuk mengetahui kelompok konsumen eksternal organisasi dimana didalamnya terdapat segmen pasar yaitu sub kelompok pembeli dalam pasar. Kebutuhan dan keinginan pembeli serta tanggapan terhadap usaha-usaha pemasaran sebuah segmen hampir sama dan berbeda diantara segmen.

Konsep pemasaran bukan hanya sekedar produk dimana produk dibuat lalu dijual, namun harus berfokus kepada customer, dapat merasakan apa yang customer rasakan dan memberikan respon yang tepat. Konsep pemasaran bukanlah sekedar mencari customer baru, namun juga memelihara customer yang ada. Kunci dari konsep pemasaran adalah mencapai tujuan organisasi dengan menjadi lebih efektif dibandingkan dengan kompetitor melalui value yang diciptakan, disampaikan, dan dikomunikasikan kepada target market

Analisis Lingkungan Eksternal dan Internal, Faktor-faktor lingkungan eksternal disebut juga lingkungan "jauh" yaitu meliputi faktor-faktor ekonomi, sosial, politik, dan teknologi. Lingkungan internal lebih bersifat pada lingkungan intern perusahaan yang berupa kekuatan dan kelemahan dari tiap-tiap divisi seperti produksi, pemasaran, sumber daya manusia ( SDM ), operasi dan keuangan. Analisis pada lingkungan internal dilakukan dalam upaya untuk mencari keunggulan-keunggulan yang dimiliki oleh suatu perusahaan yang dapat dipakai untuk membedakan diri dari pesaing ( differentiation).

\section{Segmentasi, Targeting, Positioning ( STP )}

- Segmentasi, dengan melaksanakan segmentasi pasar, kegiatan pemasaran dapat dilakukan lebih terarah dan sumber daya yang dimiliki perusahaan dapat digunakan secara lebih efektif dan efisien dalam rangka memberikan kepuasan bagi konsumen. Selain itu perusahaan dapat melakukan program-program pemasaran yang terpisah untuk memenuhi kebutuhan khas masing-masing segmen. Ada beberapa variabel segmentasi yakni : geografis, demografis, psikografis, dan perilaku.

- Targeting, setelah pasar dibagi-bagi dalam segmen-segmen, amkan perusahaan harus memutuskan suatu strategi target pasar.

- Positioning, penentuan posisi pasar menunjukan bagaimana suatu produk dapat dibedakan dari para pesaingnya.

Bauran Pemasaran adalah sejumlah alat-alat pemasaran yang digunakan perusahaan untuk meyakinkan obyek pemasaran atau target pasar yang dituju. Dalam komunikasi pemasaran ada beberapa elemen yang dipadukan yang terwujud dalam bauran komunikasi pemasaran terpadu, yaitu bauran pemasaran ( marketing mix ) Dalam marketing mix perusahaan jasa khususnya, ada unsur-unsur atau elemen yang menjadi dasar pertimbangan pengambilan keputusan dalam pembuatan strategi komunikasi pemasaran, yaitu 4P ditambah 3P : product, price, place, promotion, people, process, dan physical evidence. Dalam penelitian ini dikarenakan mengenai produk maka hanya digunakan $4 \mathrm{P}$.

\section{METODOLOGI PENELITIAN}

Pengumpulan data pada tesis ini menggunakan metode deskriptif kualitatif, keadaan dimana dilakukan pengamatan secara langsung melalui tindakan observasi lingkungan dengan melakukan pengamatan terhadap lingkungan pasar mengenai perkembangan usaha BenQ interactive flat panel dan berdasarkan dengan fakta-fakta yang ada disertai interpretasi keadaan usaha yang sebenarnya. Sumber data yang diperoleh yakni data primer, dan data sekunder 
Metode penelitian yang penulis gunakan adalah analisis SWOT. Analisis SWOT digunakan untuk merumuskan strategi pemasaran berdasarkan kekuatan, kelemahan, peluang dan ancaman Benq interactive flat panel. Tahap analisis dilakukan dengan membuat matrik IFAS (Internal Strategy Factors Analyis Summary) berdasarkan kekuatan dan kelemahan yang dimiliki oleh perusahaan dan matrik EFAS (Eksternal Strategy Factors Analyis Summary) berdasarkan peluang dan ancaman yang dihadapi oleh perusahaan.

\section{HASIL DAN PEMBAHASAN}

- Analisis SWOT

\begin{tabular}{|l|l|l|c|c|}
\hline Matriks EFE ( External Factor Evaluation ) \\
\hline No & \multicolumn{1}{|c|}{ Keterangan } & Bobot & Rating & Total \\
\hline & Opportunities & & \\
\hline & $\begin{array}{l}\text { Pengadaan kebutuhan monitor di } \\
\text { pemerintahan setiap tahun terus } \\
\text { meningkat dari sisi anggaran maupun } \\
\text { total proyek }\end{array}$ & 0.3 & 4 & 1.2 \\
\hline 2 & $\begin{array}{l}\text { Bekerja sama dengan dengan sistem } \\
\text { integrator }\end{array}$ & 0.25 & 3 & 0.75 \\
\hline 3 & $\begin{array}{l}\text { Sekolah internasional merupakan salah } \\
\text { satu target penjualan yang cukup besar di } \\
\text { Indonesia }\end{array}$ & & & \\
\hline Threats 0.1 & 2 & 0.2 \\
\hline 1 & $\begin{array}{l}\text { Kompetitor dengan produk yang sejenis } \\
\text { menawarkan harga yang lebih murah } \\
\text { dengan fitur standar }\end{array}$ & & & \\
\hline 2 & $\begin{array}{l}\text { Banyak perusahaan berlomba untuk } \\
\text { mencari produk sejenis untuk } \\
\text { diperjualbelikan di pasar Indonesia } \\
\text { seperti produk buatan negara China }\end{array}$ & & & \\
\hline 3 & $\begin{array}{l}\text { Produk substitusi yang masih menjadi } \\
\text { solusi yang lebih murah }\end{array}$ & 0.1 & 2 & 0.2 \\
\hline & Total 0.1 & 2 & 0.2 \\
\hline
\end{tabular}

Hasil :

Total perkalian antara bobot dengan rating yang menunjukkan angka 3 dapat diartikan sebagai kemampuan produk BenQ interactive flat panel dalam mengatasi ancaman berada diatas rata-rata atau menunjukan bahwa produk BenQ interactive flat panel memiliki kemampuan untuk meraih kesempatan yang ada. 


\begin{tabular}{|c|c|c|c|c|}
\hline No & Keteranoan & Bohot & Rating & Totol \\
\hline & Strengths & & & \\
\hline 1 & $\begin{array}{l}\text { Fitur yang unggul dibandingkan } \\
\text { dengan kompetitor lain }\end{array}$ & 0.2 & 4 & 0.4 \\
\hline 2 & Mempunyai kualitas layar yang bagus. & 0.03 & 2 & 0.06 \\
\hline 3 & $\begin{array}{l}\text { Mempunyai harga yang kompetitif } \\
\text { jika dibandingkan dengan para } \\
\text { kompetitor. }\end{array}$ & 0.1 & 3 & 0.45 \\
\hline 4 & $\begin{array}{l}\text { PT Datascrip mempunyai infrastruktur } \\
\text { yang mendukung serta tersertifikasi } \\
\text { dengan baik }\end{array}$ & 0.2 & 3 & 0.6 \\
\hline 5 & $\begin{array}{l}\text { PT Datascrip mempunyai layanan } \\
\text { purna jual untuk setiap produk yang } \\
\text { diperjualbelikan }\end{array}$ & 0.1 & 3 & 0.3 \\
\hline 6 & $\begin{array}{l}\text { PT Datascrip mempunyai jumlah sales } \\
\text { yang cukup banyak }\end{array}$ & 0.07 & 3 & 0.21 \\
\hline & Weaknesses & & & \\
\hline 1 & $\begin{array}{l}\text { Jalur penjualan untuk BenQ } \\
\text { interactive flat panel masih kurang } \\
\text { banyak }\end{array}$ & 0.15 & 2 & 0.3 \\
\hline 2 & $\begin{array}{l}\text { Tim sales yang tidak fokus dalam } \\
\text { menjual produk BenQ interactive flat } \\
\text { panel }\end{array}$ & 0.1 & 3 & 0.3 \\
\hline 3 & $\begin{array}{l}\text { Produk BenQ interactive flat panel } \\
\text { belum melakukan kegiatan branding } \\
\text { yang gencar }\end{array}$ & 0.05 & 2 & 0.1 \\
\hline & Total & 1 & & 2.72 \\
\hline
\end{tabular}

Hasil :

Total perkalian antara bobot dengan rating yang menunjukkan angka 2.72 dapat diartikan bahwa internal manajemen PT Datascrip cukup kuat. Walaupun adanya kelemahan-kelemahan, perusahaan harus terus melakukan berbagai macam perbaikan dan mengembangkan kekuatan yang dimiliki.

\section{- Matching Stage}

EFE Matriks dan IFE Matriks yang sudah dijelaskan pada subbab sebelumnya akan menghasilkan matriks gabungan IE Matriks yang dapat menentukan posisi perusahaan. Berikut merupakan matriks gabungan nya : 


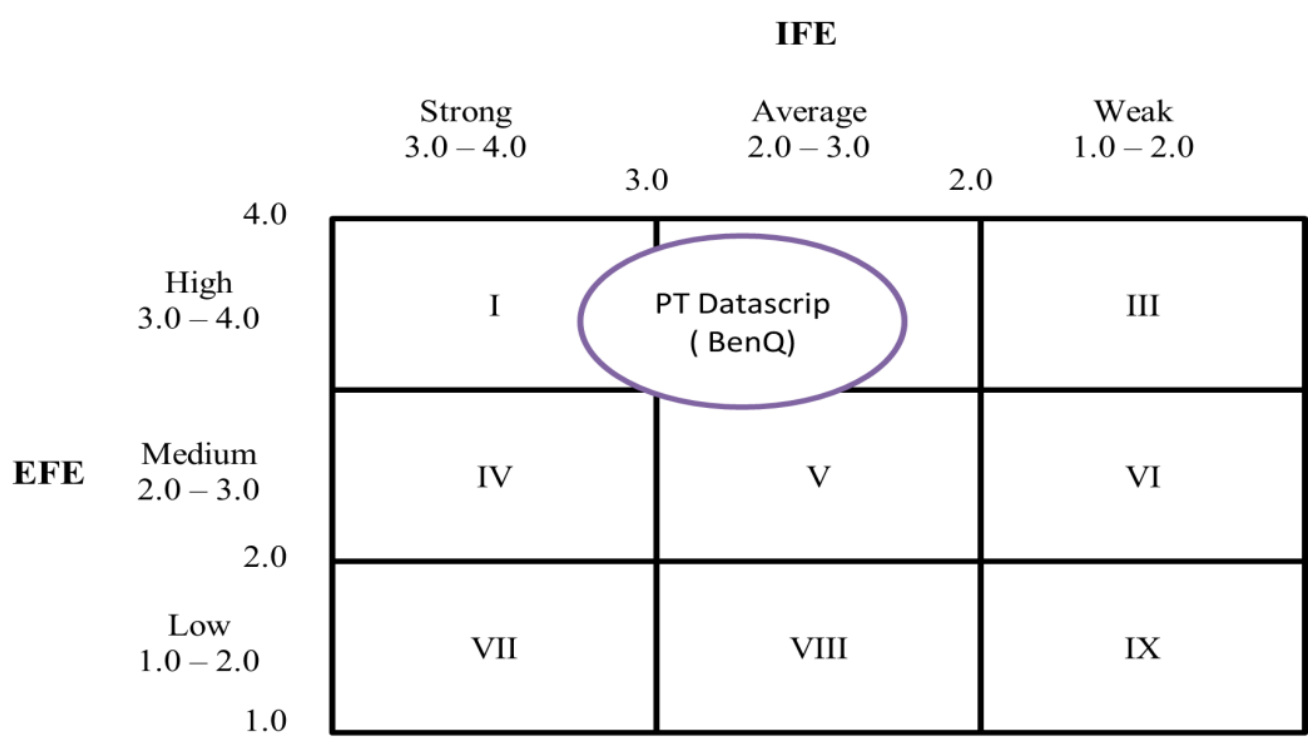

IE Matriks diataas menunjukan bahwa PT Datascrip ( BenQ ) berada di kuadran II, dengan nilai EFE 3.0 dan IFE 2,72 yang berarti PT Datascrip ( BenQ ) berada dalam posisi Grow and Build. Posisi grow and build menunjukan bahwa posisi eksternal dan internal yang kuat. Strategi pemasaran yang biasa dilakukan pada posisi seperti ini yakni strategi market development, market penetration, dan product development. Hal ini akan menjadi dasar bagi penulis dalam mendapatkan strategi yang tepat pada analisis selanjutnya.

\section{- Segmenting, Targeting, dan Positioning}

- Segmentasi

- Segmentasi Berdasarkan Geografis, 91\% penjualan dari BenQ interactive flat panel berasal dari daerah pulau Jawa, namun jika lebih dispesifik lagi maka di daerah Jabodetabek.

- Segmentasi Berdasarkan Demografis, Kalangan eksekutif manajemen dalam suatu perusahaan seperti direktur atau yang setara.

- Segmentasi Berdasarkan Psikografis, Produk BenQ interactive flat panel banyak digunakan oleh pimpinan ( perusahaan maupun pemerintahan ) yang memiliki gaya hidup yang simple dan mewah

- Targeting, target utama dari produk BenQ interactive flat panel ini adalah dari segmen pemerintahan

○ Positioning, Produk dengan teknologi smart eye care dan anti-bakteria

\section{- Analisis Bauran Pemasaran}

Bauran pemasaran terdiri dari produk, price, promosi, dan place yang saling bersinergi antara satu dan lainnya. Oleh karena itu, maka disusunlah bauran pemasaran sebagai berikut :

- Product, produk BenQ interactive flat panel mempunyai beberapa keunggulan dibanding dengan kompetitor sejenis seperti mempunyai fitur InstaQShare dimana fitur ini berfungsi sebagai perangkat lunak yang dirancang untuk presentasi dan kolaborasi nirkabel ( dupilkasi konten ke beberapa device sebanyak 16 device ) yang lancar selama melakukan kegiatan presentasi dengan kelancaran streaming dokumen visual dan audio, dan video berkualitas 4K. BenQ interactive flat panel juga mempunyai fitur EZWrite 4.0 yang merupakan aplikasi papan tulis yang dirancang untuk memfasilitasi 
pembelajaran / presentasi menjadi lebih interaktif seperti mengilustrasikan gagasan, merekam catatan, diskusi, mengirimkan hasil diskusi via email, QRcode, dan langsung di print via wifi.

- Price, harga untuk BenQ interactive flat panel berdasarkan observasi yang dilakukan dibandingkan dengan kompetitor masih diharga yang kompetitif. Perbandingan harga ini bisa dilihat ditabel dibawah ini.

\begin{tabular}{|l|c|c|c|c|}
\hline \multirow{2}{*}{$\begin{array}{c}\text { Tipe } \\
\text { Ukuran }\end{array}$} & \multicolumn{4}{|c|}{ Harga ( dalam rupiah ) } \\
\cline { 2 - 5 } & BenQ & Viewsonic & Infocus & Smartboard \\
\hline $55^{\prime \prime}$ & $52,000,000$ & $52,000,000$ & - & - \\
\hline $65^{\prime \prime}$ & $74,000,000$ & $71,955,000$ & $370,000,000$ & $216,650,000$ \\
\hline $70^{\prime \prime}$ & $104,000,000$ & - & - & $307,930,000$ \\
\hline $75^{\prime \prime}$ & $123,000,000$ & $129,500,000$ & - & - \\
\hline $86^{\prime \prime}$ & $182,000,000$ & $231,000,000$ & - & $432,950,000$ \\
\hline
\end{tabular}

Berdasarkan dari tabel perbandingan harga, bisa dilihat bahwa harga dari BenQ interactive flat panel masih ada posisi harga yang normal. Namun jika mengacu pada market share seperti pada penjelasan sebelum nya dimana jika dibandingkan dengan penjualan produk Infocus dan brand Smartboard yang mempuyai harga yang lebih tinggi namun penjualannya lebih besar. Hal ini sangat jauh jika dibandingkan dengan produk BenQ interactive flat panel yang harga lebih murah namun penjualan masih kalah dibandingkan produk Infocus. Maka dari itu, banyak aspek yang mempengaruhi dari anomali ini yakni tim sales produk Infocus dan Smartboard yang fokus, tim sales yang mempunyai banyak jalur penjualan, benefit dari produk yang lebih menarik dan lainnya.

- Promotion, kegiatan promosi yang dilakukan oleh tim PT Datascrip dalam memperkenalkan produk BenQ interactive flat panel yakni dengan membuat email mengenai penjelasan produk, study case yang dikirimkan kepada seluruh pelanggan PT Datascrip maupun partner agar mereka selalu ingat jika PT Datascrip menjual BenQ interactive flat panel. Kegiatan promosi lain juga dilakukan berupa acara-acara yang mengundang partner dalam sebuah acara gathering serta mengadakan seminar untuk pemerintahan dibeberapa daerah diluar Jakarta ( Pulau Sumatera, Kalimantan, Sulawesi )

- Place, jalur distribusi untuk produk BenQ interactive flat panel saat ini masih langsung kepada pelanggan ( end user )

\section{KESIMPULAN DAN SARAN}

\section{Kesimpulan}

Beberapa kesimpulan mengenai strategi pemasaran yang dilakukan dalam rangkan meningkatkan penjualan dari produk ini, yakni :

1. Segmentasi yang dilakukan masih terfokus kepada daerah pulau Jawa khususnya Jabodetabek, dimana seperti pada penjelasan sebelumnya seluruh pusat perkantoran maupun pemerintahan terdapat di geografis ini serta masih didominasi digunakan oleh para pimpinan ( baik di perusahaan swasta maupun pemerintahan )

2. Targeting yang dilakukan sejauh ini masih kepada segmen pemerintahan karena memiliki dana yang lebih banyak.

3. Positioning untuk produk BenQ interactive flat panel yakni produk yang memiliki teknologi smart eye care dan anti bakteria yang aman untuk penggunanya. 
4. Produk BenQ interactive flat panel adalah produk yang unggul dari segi fitur yang lebih lengkap seperti dilengkapi dengan fitur InstaQshare ( fitur mirroring ) yang telah beresolusi $4 \mathrm{~K}$, fitur EZWrite 4.0 yang memungkinkan pembawa presentasi dapat merekam semua penjelasan baik tulisan maupun suara serta memiliki sertifikat resmi untuk teknologi smart eye care dan anti-bakteria.

5. Harga dari produk BenQ interactive flat panel masih tergolong kompetitif jika dibandingkan dengan produk kompetitor.

6. Kegiatan promosi yang dilakukan PT Datascrip untuk memperkenalkan sudah cukup baik seperti melakukan roadshow ke beberapa wilayah / kota besar di Indonesia,

7. Distribusi produk yang dilakukan oleh tim penjualan dari PT Datascrip sejauh ini yakni masih langsung kepada end user yang mana hal ini tentunya sangat terbatas dikarenakan sumber daya manusia

\section{Saran}

Berdasarkan dari penelitian yang telah dilakukan, terdapat beberapa rekomendasi strategi sebagai masukan dan bahan pertimbangan bagi perusahaan PT Datascrip dalam menjual produk BenQ interactive flat panel yakni

1. Penulis menyarankan agar PT Datascrip juga dapat memperluas segmentasi geografis dengan memanfaatkan kantor cabang yang dimiliki oleh PT Datascrip di 11 kota yang ada di seluruh Indonesia.

2. Penulis menyarankan targeting dikembangkan seperti ke perusahaan swasta yang sudah multinasional maupun cabang dari luar negeri, serta sekolah-sekolah dan universitas yang mempunyai standar internasional

3. Penulis menyarankan produk BenQ interactive flat panel harus melakukan pengembangan produk terutama dari sisi software agar semakin menambah nilai jual dari produk ini

4. Kegiatan promosi untuk memperkenalkan produk BenQ interactive flat panel perlu dikembangkan dengan memanfaatkan media online atau digital.

5. Proses distribusi produk BenQ interactive flat panel perlu dikembangkan dengan memanfaatkan partner yang berkomitmen untuk menjual produk ini.

\section{DAFTAR PUSTAKA}

\section{BUKU}

Aaker, David. A. (1992). Strategic Market Management: Third Edition. Canada: John Wiley \& Sons, Inc.

Alma, H. Buchari. (2003). Pemasaran Stratejik Jasa Pendidikan. Bandung: Alfabeta.

Armstrong, Gary dan Kotler. Philip (2000). Dasar-Dasar Pemasaran (Jilid 2), Jakarta : PT. Prehalindo, h.5-37.

Bearden, William O., Ingram, Thomas N., \& La Forge, Raymond W. Marketing: Principles and Perspectives: Fifth Edition. McGraw-Hill, Inc.

Basrowi dan Sudikin. (2002). Metode Penelitian Kualitatif Persepektif Mikro.Surabaya: Ihsan Cendikia.

Boyd JR, Harper W., Orville C. Walker JR, \& Jean-Claude Larreche (1998), Marketing Management: A Strategic Approach With A Global Orientation, Irwin McGrawwHill, International Edition.

Chandra, Gregorius. (2002). Strategi dan Program Pemasaran. Yogyakarta: Andi.

Cravens, David W. (2000). Strategic Marketing: Sixth Edition. USA: McGraw-Hill Companies, Inc.

Daft, L.Richard and Marcic, Dorothy (2009). Understanding Management, Mason-Ohio : South-Western Cengage Learning. 
David, R.Fred (1991). Concept of Strategic Management $\left(4^{\text {th }}\right.$ ed.), Mac Millan Publishing Company.

David, R.Fred (2006). Strategic Management : Concept and cases $\left(10^{\text {th }}\right.$ ed.), New Jersey : Pearson Education - Prentice Hall.

Guiltinan, P. Joseph and Paul W. Gordon (1992), Strategi dan Program Manajemen Pemasaran (2th ed.), Jakarta: Penerbit Erlangga.

Hax, Arnold C. And Nicholas S. Majluf (1991). The Strategy Concept and Process, A Pragmatic Approach, Prentice Hall Inc.

Hill, Charles WL, \& Jones, Gareth R. (1998). Strategic Management an Integrated Approach ( $4^{\text {th }}$ ed. $)$, New York, Houghton Mifflin Company

Hill, A. Michael, Ireland R. Duane, Hoskisson E. Robert (1998). Strategic Management Competitiveness and Globalization, St.Paul, West Publisting Company.

Jauch, R.Lawrence and Gluech, F. Wiliam, (1998). Business Policy and Strategic Management ( $5^{\text {th }}$ ed.), New York: McGraw-Hill

Kotler, Philip (1996). Marketing Management:Ninth Edition. USA: Prentice Hall,Inc.

Mintzberg, Henry., Quinn, James B., Voyer, John. (1995). The Strategy Process: Collegiate Edition. USA: Pretince-Hall, Inc.

Nasution, S.(2003). Metode Reseacrh ( Penelitian Ilmiah). Jakarta: PT Bumi Aksara

Pearce II, John A, and Richard B. Robinson, JR (2000). Strategic Management: Formulation, Implementation and Control ( $7^{\text {th }}$ ed.), Irwin McGraw-Hill

Porter, Michael E (1980). Competitive Strategy, Technic for Analyzing Indexs \& Competitors, The Free Press.

Stauble, Vermon R. (2000). Marketing Strategy: A Global Perspective. USA: Harcourt, Inc.

Stanton, William J., Etzel, Michael J., Walker, Bruce J. (1991). Fundamentals of Marketing: Ninth Edition. USA: McGraw-Hill, Inc.

\section{INTERNET}

https://sirup.lkpp.go.id/sirup 


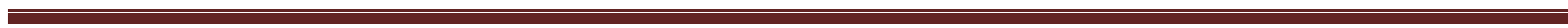
$\cdot$ 